\title{
Correlation between Foot Arch Index and the Intensity of Foot, Knee, and Lower Back Pain among Pregnant Women in a South-Eastern Nigerian Community
}

\author{
Chidiebele Petronilla Ojukwu ${ }^{a} \quad$ Emeka Godson Anyanwu ${ }^{b}$ \\ Ginika Gladys Nwafor ${ }^{a}$ \\ Departments of ${ }^{\mathrm{a}}$ Medical Rehabilitation and ${ }^{\mathrm{b}}$ Anatomy, College of Medicine, University of Nigeria, Enugu, Nigeria
}

\section{Significance of the Study}

- This study showed a prevalence of low-arched feet among pregnant women. There was no correlation between the foot arch index and intensities of pregnancy-related foot, knee, and lower back pain. Collapse of the arch height during pregnancy was not found to have affected the proximal joint disorders. Therapeutic care of the foot during pregnancy is recommended.

\section{Keywords}

Foot arch height index · Knee pain · Foot pain · Lower back pain · Pregnancy

\begin{abstract}
Objectives: The aim of this study was to assess the arch height index of pregnant women and its correlation with foot pain, anterior knee pain, and lower back pain. Subjects and Methods: Two hundred and fifteen consenting pregnant women participated in this cross-sectional study. The arch height index was assessed from their foot prints, while pain intensity was rated on a numerical rating scale. Data were summarized with descriptive statistics and the Pearson correlation was used to determine correlations between the variables at $p<0.05$. Results: Of the 215 pregnant women, $123(57.2 \%)$ and 127 (59.9\%) had low arch heights on the right and left feet, respectively, and the mean arch height
\end{abstract}

\begin{tabular}{ll}
\hline KARGER & $\begin{array}{l}\text { ( ) 2017 The Author(s) } \\
\text { Published by S. Karger AG, Basel }\end{array}$ \\
$\begin{array}{l}\text { E-Mail karger@karger.com } \\
\text { www.karger.com/mpp }\end{array}$ & $\begin{array}{l}\text { This is an Open Access article licensed under the Creative Commons } \\
\text { Attribution-NonCommercial-4.0 International License (CC BY-NC) } \\
\text { (http://www.karger.com/Services/OpenAccesLicense), applicable to } \\
\text { the online version of the article only. Usage and distribution for com- } \\
\text { mercial purposes requires written permission. }\end{array}$
\end{tabular}

indices were $0.27 \pm 0.71$ for the right foot and $0.28 \pm 0.07$ for the left foot. The prevalence of foot, knee, and lower back pain was 65 (30.2\%), 43 (20.0\%), and 93 (43.3\%), respectively. The Pearson correlation analysis did not reveal any significant relationship ( $p>0.05$ ) between foot pain and each of the right $(r=-0.010, p=0.886)$ and left $(r=0.004, p=0.955)$ arch indices as well as between knee pain and each of the right $(r=0.042, p=0.536)$ and left $(r=0.045, p=0.515)$ arch indices. A similar trend was observed for the lower back, which also did not show any significant relationship to each of the right $(r=0.026, p=0.703)$ and left $(r=0.097, p=0.157)$ arch indices. Conclusion: The study participants had a high prevalence of low foot arches, indicating pes planus. Lower back pain was more common than foot and knee pain. The foot arch heights did not show any relationships between the intensities of foot, anterior knee, and lower back pain.

(c) 2017 The Author(s) Published by S. Karger AG, Basel

Chidiebele Petronilla Ojukwu

Department of Medical Rehabilitation, Faculty of Health Sciences and Technology University of Nigeria

Enugu (Nigeria)

E-Mail chidiebele.ojukwu@ unn.edu.ng 


\section{Introduction}

Pregnancy is associated with several alterations of the body's systems, including hormonal and musculoskeletal changes [1]. Pelvic and spinal joints as well as the ligaments are relaxed and capable of greater motion during pregnancy due to the influence of relaxin and estrogen, which are produced by the ovaries [2]. However, the integrity of connective tissues is compromised, leading to an increase in joint mobility and increased risk of ligamentous injuries [3], which are commonly observed during pregnancy. The foot is also prone to pregnancy-related changes because overpronation of the foot may develop as a consequence of relaxation of its connective tissues [4]. This further increases the stress on the foot and joint structures that maintain the stability of the foot arches. The arches of the foot, most importantly the medial longitudinal arches, add to its weight-bearing capacity and resiliency [5]. Hormonal and physical changes during pregnancy compromise the integrity of the supporting soft tissues of the foot arches through joint laxity due to the effect of relaxin and other hormones and the increased body weight [1]. A decrease in arch height leads to a loss of the longitudinal arch (pes planus) and has been reported during pregnancy, with the majority of cases lasting into postpartum periods and beyond [6]. This pregnancy-related decrease in arch height usually results from hormonal and physical changes, including increased ligamentous laxity, weight gain, and a shift in the center of gravity [2, $3,5-9]$. The loss of arch height affects the weight bearing of the foot, resulting to pain, irritation, or discomfort in the foot and other lower limb joints [3] due to the synchrony in their biomechanics [8]. Therefore, unusual or prolonged stress in the foot can affect the biomechanics and functioning of proximal joints, which commonly translates into pain at the knee, hip, pelvis, and lower back. Previous studies [9-12] have shown significant relationships among pes planus and knee pain, hip, and lower back symptoms in many populations, but there is limited information on these relationships during pregnancy.

Women's healthcare practices in Nigeria have not given much consideration to the integrity of the supporting structures of the foot and their associated complications in other proximal joints during pregnancy, and hence the assessment, management, and prevention of musculoskeletal problems among pregnant women are not managed properly. Therefore, the objective of this study was to determine if there are any relationships

Foot Arch Index and Proximal Joint Pain in Pregnant Women
Table 1. Sociodemographic characteristics of the participants $(n=215)$

\begin{tabular}{lc}
\hline Variables & $n(\%)$ \\
\hline Body mass index & \\
$18.00-24.99$ & $97(45.1)$ \\
$25.00-29.99$ & $69(32.1)$ \\
$\geq 30$ & $49(22.8)$ \\
Age & $74(34.4)$ \\
$18-23$ years & $92(42.8)$ \\
$24-29$ years & $38(17.7)$ \\
$30-34$ years & $11(5.1)$ \\
$35-40$ years & $13(6.0)$ \\
Gestational trimesters & $79(36.7)$ \\
First & $123(57.2)$ \\
Second & \\
Third &
\end{tabular}

between the arch height index (AHI) of the medial-longitudinal arch and intensity of foot, knee, and lower back pain among pregnant Nigerian women.

\section{Materials and Methods}

A total of 215 pregnant women (age range 18-40 years) participated in this cross-sectional study. The participants were recruited from the antenatal clinics of 4 government hospitals in Enugu, Nigeria. The exclusion criteria were amputations of a lower limb, recent surgeries affecting locomotion, previous lower limb or spinal joint surgery or trauma, and chronic diseases affecting collagen metabolism.

The University of Nigeria Health Research and Ethics Committee reviewed and approved this study and written informed consent was obtained from the participants before enrollment. Obstetric information was obtained directly from each participant and body mass $(\mathrm{kg})$ and height (meters) were measured to calculate body mass index as $\mathrm{kg} / \mathrm{m}^{2}$. In addition, information on pregnancyrelated medical histories, including foot, hip, and lower back pain, and any ankle, knee, or foot surgeries or injuries during the present pregnancy, was obtained directly from the participants.

A standard numerical pain rating scale was used to assess the foot, knee, and lower back pain intensities of the participants. The participants were asked to make 3 numeric ratings, corresponding to the current intensity of pain experienced in the foot, knee, and lower back. Scores on the scale ranged from 0 to 10 , with mild pain graded as $0-4$, moderate pain scored as 5 , and severe pain as $6-10$.

The static arch height indices were measured from both footprints using the method proposed by Cavanagh and Rodgers [13]. With the participants in a static standing position, they were asked to step with each foot onto a wooden board covered with talc powder and then onto a sheet of carbon paper. The imprints were traced out on a calibrated plain sheet. The truncated foot length (without the toes) of the footprint area was divided equally into 3 sections: A, the rear foot area; $\mathrm{B}$, the mid foot area, and C, the fore-

Med Princ Pract 2017;26:480-484 481 
foot area. Then, the AHI was calculated by dividing the mid foot area (B) by the total foot area (without the toes): $A H I=B /(A+B+C)$. Participants' feet were classified into 3 categories based on the principles used in a previous study [14] that classified a high arch as AHI values $<0.21$, a normal arch as ranging from 0.22 to 0.26 , and a low arch as values $>0.27$.

\section{Statistical Analysis}

The data were analyzed using SPSS software version 21 (IBM Corporation, Armonk, NY, USA), with an alpha level set at $p<$ 0.05 . Descriptive statistics (frequency, percentages, means, and standard deviations) were used to summarize the prevalence of foot, knee, and lower back pain. Inferential statistics using Pearson and partial correlations were used to determine the associations between the foot arch heights and each of foot, knee, and lower back pain

\section{Results}

The mean age of the 215 women was $25.1 \pm 4.9$ years, and mean BMI was $27.42 \pm 15.97$. The sociodemographic characteristics of the participants are presented in Table 1 . The majority (57.2\%) of the participants were in the third trimester of their pregnancies.

The foot classification of the pregnant women is presented in Table 2. In total, 123 (57.2\%) and 127 (59.9\%) women had low arches of the right and left feet, respectively. The mean AHI of the right and left feet were $0.27 \pm$ 0.71 and $0.28 \pm 0.69$, respectively. The pregnancy-related proximal joint pains in the 3 body segments among the participants were reported as follows: lower back pain, 93 (43.3\%); foot pain, 65 (30.2\%); knee pain, 43 (20.0\%); and no pain, $14(6.5 \%)$.

The Pearson and partial correlation factors between the participants' AHIs and intensities of foot, knee, and lower back pain are shown in Table 3. There was no significant relationship $(p>0.05)$ between foot pain and each of the right $(r=-0.010, p=0.886)$ and left $(r=0.004$, $p=0.955)$ arch indices. No relationship existed between knee pain and each of the right $(r=0.042, p=0.536)$ and left $(r=0.045, p=0.515)$ arch indices. Similarly, lower back pain showed no significant relationship to the right $(r=0.026, p=0.703)$ and left $(r=0.097, p=0.157)$ arch indices.

\section{Discussion}

This study revealed a high prevalence of low-arched feet (right, 57.2\%; left, 59.1\%), indicating pes planus among the participants. The presence of low arch heights
Table 2. Foot classification of the pregnant women

\begin{tabular}{llr}
\hline Foot type & \multicolumn{2}{l}{ Frequency, $n(\%)$} \\
\cline { 2 - 3 } & right & left \\
\hline Low arch & $123(57.2)$ & $127(59.1)$ \\
Normal arch & $55(25.6)$ & $47(21.9)$ \\
High arch & $37(17.2)$ & $41(19.1)$ \\
\hline Total & $215(100)$ & $215(100)$ \\
\hline
\end{tabular}

Table 3. Correlations between AHIs and intensities of foot, knee, and lower back pain

\begin{tabular}{|c|c|c|c|c|}
\hline & \multicolumn{2}{|c|}{ Pearson correlation } & \multicolumn{2}{|c|}{ Partial correlation } \\
\hline & right AHI & left AHI & \multicolumn{2}{|c|}{ right $\mathrm{AHI}$ left $\mathrm{AHI}$} \\
\hline \multicolumn{5}{|l|}{ Foot pain } \\
\hline$r$ value & -0.010 & 0.004 & 0.057 & 0.048 \\
\hline$p$ value & 0.886 & 0.955 & 0.412 & 0.491 \\
\hline \multicolumn{5}{|l|}{ Knee pain } \\
\hline$r$ value & 0.042 & 0.045 & 0.044 & 0.062 \\
\hline$p$ value & 0.536 & 0.515 & 0.530 & 0.066 \\
\hline \multicolumn{5}{|l|}{ Lower back pain } \\
\hline$r$ value & 0.026 & 0.097 & 0.025 & 0.106 \\
\hline$p$ value & 0.703 & 0.157 & 0.716 & 0.123 \\
\hline
\end{tabular}

AHI, arch height index.

among pregnant women in this study confirmed the findings of previous studies $[6,15,16]$ that reported pregnancy-related changes in the foot arches. Bohemen [15] reported a significant loss of the medial longitudinal arch in 2 pregnant women. Wetz et al. [16] also reported a slight nonsignificant decrease in the arch height of 40 pregnant women. In a recent study, Dunn et al. [6] reported that $65.7 \%$ of the parous women in their study had low arch heights with an associated increase in shoe size. Changes in the structure of the foot, particularly decreased arch heights, might be consequential to the changes in the body biomechanics resulting from forward displacement of the body mass during pregnancy. Secondly, pregnancy-related increases in body mass could increase the load transferred to the distal body segments. Hormones, including relaxin and estrogen, can have an influence during pregnancy as their laxity effects on the cervical tissues may also affect the ligaments supporting the foot arches [17]. According to Segal et al. [18], "the combination of ligamentous laxity in the arch, increased body mass and the shift in the center of pressure towards
482
Med Princ Pract 2017;26:480-484 DOI: $10.1159 / 000481622$
Ojukwu/Anyanwu/Nwafor 
the posterior part of the foot during pregnancy may contribute to change in length of the ligaments supporting the arch, leading to loss of arch height."

The participants in the present study reported pregnancy-related foot, knee, and lower back pains, with lower back pain being the most common. This finding corroborates previous studies that reported the prevalence of foot [19], knee [20], and lower back [19] pain among pregnant women. An increased risk for such musculoskeletal problems was related to the biochemical and biomechanical changes that occur in a woman's body during pregnancy [18]. The pregnancy-related increase in body mass in addition to the effect of the hormone relaxin [21] during pregnancy are potential precursors of atypical stresses on the musculoskeletal system, with resultant joint pain. In addition, biomechanical changes in the foot $[16,22]$, loss of arch height $[18,22]$, and changes in gait pattern [23] during pregnancy are major factors contributing to foot pain in pregnant women. Pregnancy-related laxity in the knee joint, particularly cruciate ligament laxity [24] and chondromalacia of the patella [25], have been associated with increased knee pain during pregnancy. Furthermore, pregnancy-related lower back pain, the most widely studied condition, has been attributed to several factors, including, hormonal-mediated joint laxity, vascular changes, postural changes resulting from the increasing growth of the fetus [26], muscular dysfunctions [25], and decreased back muscle endurance [27], among others.

In the present study, no significant correlations were found between the AHI and each of the foot, knee and lower back pain intensities of the participants. In contrast, relationships between the structure of the medial longitudinal arch and proximal joint pain were previously reported across several populations $[9,10,12,18,28]$. It has been explained that resultant changes in foot biomechanics associated with changes in the foot structure can alter the normal control of forces propagating from the foot to more proximal lower limb joints and the spine $[10,18]$, and may contribute to pain in the feet, knees, and hips $[9,18]$. Foot dysfunctions can result in overuse syndromes, muscle imbalances, abnormal joint alignment, and increased stresses on the surrounding soft tissues in compensation for limitations of the foot [9], with possible resultant foot pain. The resultant excessive foot pronation typical of low-arched feet has been associated with a higher incidence of knee pain [9]. Cho et al. [12] also established associations between the mechanical axis alignment of the lower limb and osteoarthritis severity, while Kosashvili et al. [28] found that moderate and severe pes planus was associated with a nearly doubled rate of ante-

Foot Arch Index and Proximal Joint Pain in Pregnant Women rior knee pain and intermittent lower back pain. Gross et al. [11] posited that such associations between foot changes and knee pain might be expected if the postural alterations that accompany planus foot morphology also result in a tendency for the femur to accompany the tibia in internal rotation. This is because excessive femoral internal rotation, if it occurs, could cause the lateral trochlea femoris to abut against the lateral patella. Also, when planus foot morphology is accompanied by a more proximal bony malalignment there is a tendency for increased contact between the articulating surfaces of the lateral patellofemoral joint, which results in excessive joint stress and cartilage damage [11]. These imply that, in addition to planus foot morphology, a combination of other factors, including possible resultant femoral anteversion, external tibial torsion, and an excessive valgus quadriceps angle (Q-angle), may be responsible for the mechanical overload and stress of the lateral patellofemoral joint [29]. Similar to a limitation of the study by Gross et al. [11], the present study did not assess femoral anteversion, tibial torsion, or the Q-angle for the purpose of establishing a more definite and specific relationship between the foot structure and the incidence of knee pain during pregnancy. Another factor which may explain the absence of a correlation between $\mathrm{AHI}$ and foot and knee pains in the present study is that $\mathrm{AHI}$ in each foot was not specifically correlated with pregnancy-related pains in the ipsilateral foot and knee joints.

Considering lower back pain, the present study contradicted the results of a previous study [30] that showed associations between changes in foot morphology, particularly pes planus morphology with its associated excessive foot pronation, and the incidence of lower back pain. In their study, Pinto et al. [30] reported that excessive foot pronation is associated with the occurrence of lower back pain, which they explained by establishing a consecutive sequence of events occurring in the musculoskeletal system. According to their deductions from previous studies, there is a linear relationship among increased foot pronation, excessive calcaneal eversion, increased pelvic anteversion, lumbar hyperlordosis, and the occurrence of pathological conditions of the lumbar spine. The contradictory findings reported here regarding correlations between foot structure and lower back pain may be attributed to the cross-sectional design of the study. A longitudinal study that monitors the changes in AHI at various stages of gestation will offer better grounds for establishing correlations between pregnancy-related changes in foot structure and the occurrence of lower back pain, and generally in the other proximal lower limb joints.

Med Princ Pract 2017;26:480-484 DOI: $10.1159 / 000481622$ 


\section{Conclusion}

In this study, low foot arches, indicating pes planus, were highly prevalent among the pregnant women, with dominance in the left foot. There was no association among the foot arch heights and the intensities of foot, anterior knee, and lower back pains experienced during pregnancy. Therapeutic interventions aimed at maintain- ing the integrity of the foot structures during pregnancy is recommended. Further longitudinal studies are also required to better assess the relationship between the arch index and the intensity of pain or musculoskeletal changes in the proximal joints of the lower limbs, as well as determining the other causes of foot, knee, and lower back pains during pregnancy.

\section{References}

1 Rössner S: Weight gain in pregnancy. Hum Reprod 1997;12:110-115.

2 Ribas SI, Guirro EC: Analysis of plantar pressure and postural balance during different phases of pregnancy. Braz J Phys Ther 2007; 11:391-396.

3 Kravitz L, Heyward VH: Flexibility training. http//www.drlenkravitz.com (accessed September 21, 2015).

4 Larzarus JH, Premawardhana LD: Screening for thyroid disease in pregnancy. Am J Clin Pathol 2005;58:449-452.

5 Egwu OA, Okafor IJ, Ukoha U, et al: Pes planus. Int J Adv Res 2012;03:166.

6 Dunn J, Dunn C, Habbu R, et al: Effect of pregnancy and obesity on arch of foot. J Orthop Surg 2012;4:101-104.

7 Guyton AC, Hall JE: Textbook of Medical Physiology, ed 11. Philadelphia, Saunders, 2005.

8 Powers CM: The influence of abnormal hip mechanics on knee injury: a biomechanical perspective. J Orthop Sports Phys Ther 2010; 40:42-51.

9 Dahle LK, Mueller M, Delitto A, et al: Visual assessment of foot type and relationship of foot type to lower extremity injury. J Orthop Sports Phys Ther 1991;14:70-74.

10 Erhart JC, Mündermann A, Mündermann L, et al: Predicting changes in knee adduction moment due to load-altering interventions from pressure distribution at the foot in healthy subjects. J Biomech 2008;41:29892994.
11 Gross KD, Felson DT, Niu J, et al: Association of flat feet with knee pain and cartilage damage in older adults. Arthritis Care Res 2011; 63:937-944.

12 Cho Y, Ko Y, Lee W: Relationships among foot position, lower limb alignment, and knee adduction moment in patients with degenerative knee osteoarthritis. J Phys Ther Sci 2015; 27:265-268.

13 Cavanagh PR, Rodgers MM: The arch index: a useful measure from footprints. J Biomech 1987;20:547-551.

14 Hernandez AJ, Kimura LK, Laraya MHF, et al: Calculation of Staheli's plantar arch index and prevalence of flat feet: a study with 100 children aged 5-9 years. Acta Ortop Bras 2007;15: 68-71.

15 Bohemen EK: Flatfeet in pregnancy. Br J Rheumatol 1996;35:396-397.

16 Wetz HH, Hentschel J, Drerup B, et al: Changes in shape and size of the foot during pregnancy (in German). Orthopade 2006;35: 1124, 1126-1130.

17 McCrory JL, Harrison KD, Mancinelli CA, et al: The effect of added weight on foot anthropometry in pregnant women and controls. Med Sci Sports Exerc 2016;48:493.

18 Segal NA, Boyer ER, Teran-Yengle P, et al: Pregnancy leads to lasting changes in foot structure. Am J Phys Med Rehabil 2013;92: 232-240.

19 Ramachandra P, Maiya AG, Kumar P, et al: Prevalence of musculoskeletal dysfunctions among Indian pregnant women. J Pregnancy 2015;2015:437105.

20 Bányai T, Haga A, Gera L, et al: Knee joint stiffness and proprioception during pregnancy. J Orthop 2009;1:29-32.
21 Marnach ML, Ramin KD, Ramsey PS, et al: Characterization of the relationship between joint laxity and maternal hormones in pregnancy. Obstet Gynecol 2003;101:331-335.

22 Block RA, Hess LA, Timpano EV, et al: Physiologic changes in the foot during pregnancy. J Am Podiatr Med Assoc 1985;75:297-299.

23 Jelen K, Tetkova Z, Halounova L, et al: Shape characteristics of the foot arch: dynamics in the pregnancy period. Neuro Endocrinol Lett 2005;26:752-756.

24 Dumas GA, Reid JG: Laxity of knee cruciate ligaments during pregnancy. J Orthop Sports Phys Ther 1997;26:2-6.

25 Gutke A, Östgaard HC, Öberg B: Predicting persistent pregnancy-related low back pain. Spine 2008;33:E386-E393.

26 Rungee JL: Low back pain during pregnancy. Orthopedics 1993;16:1339-1344.

27 Mbada CE, Ayanniyi O, Adedoyin RA: Reference values of static back extensor muscle endurance in healthy Nigerian adults. Med Princ Pract 2009; 18:345-350.

28 Kosashvili Y, Fridman T, Backstein D, et al: The correlation between pes planus and anterior knee or intermittent low back pain. Foot Ankle Int 2008;29:910-913.

29 Earl JE, Vetter CS: Patellofemoral pain. Phys Med Rehabil Clin N Am 2007;18:439-458.

30 Pinto RZ, Souza TR, Trede RG, et al: Bilateral and unilateral increases in calcaneal eversion affect pelvic alignment in standing position. Man Ther 2008;13:513-519. 